Ashar, et al/Jurnal Ekonomi Syariah Teori dan Terapan Vol. 6 No. 5 Mei 2019: 1057-1071; IMPLEMENTASI METODE CIBEST (CENTER OF ISLAMIC BUSINESS AND ECONOMIC STUDIES) DALAM MENGUKUR PERAN ZAKAT PRODUKTIF TERHADAP PEMBERDAYAAN MUSTAHIQ DI LEMBAGA YAYASAN DANA SOSIAL ALFALAH (YDSF) SURABAYA

\title{
IMPLEMENTASI METODE CIBEST (CENTER OF ISLAMIC BUSINESS AND ECONOMIC STUDIES) DALAM MENGUKUR PERAN ZAKAT PRODUKTIF TERHADAP PEMBERDAYAAN MUSTAHIQ DI LEMBAGA YAYASAN DANA SOSIAL AL-FALAH (YDSF) SURABAYA ${ }^{1}$
}

\author{
Muhammad Afthon Ashar \\ Departemen Ekonomi Syariah- Fakultas Ekonomi dan Bisnis-Universitas Airlangga \\ Emai; afthonashar2nd@gmail.com \\ Muhammad Nafik H.R \\ Departemen Ekonomi Syariah- Fakultas Ekonomi dan Bisnis-Universitas Airlangga \\ Email: muhammadnafik@feb.unair.ac.id
}

\begin{abstract}
:
Productive zakat is the management of zakat funds by providing assistance in the form of business activity funds to mustahiq. The purpose of productive zakat funds to the community is to improve the economic welfare of mustahia. CIBEST (Center of Islamic Business and Economic Studies) is a method of measuring mustahiq poverty that is based not only on material aspects, but spiritual mustahiq before and after obtaining assistance from zakat funds. This study aims to determine the condition of mustahia poverty before and after receiving assistance from zakat funds Al-Falah Social Fund Foundation, Surabaya City. The approach used in research is a quantitative approach with case studies. In the technique of collecting data using interview techniques directly to Mustahiq based on questionnaires. The result of this study is that there is a change in the condition of the Mustahiq Quadrant I family (Prosperous) before getting zakat assistance, namely 3 heads of families to 5 heads of families. Quadrant II (Material Poverty) before getting zakat assistance, namely 1 family head, 0 family heads. Quadrant III (Spiritual Poverty Index) before getting help from one family head, 3 family heads. Quadrant IV (Absolute Poverty) before getting zakat assistance, namely 4 heads of families, becomes 0 family heads.
\end{abstract}

Keywords: Productive Zakat, CIBEST, Mustahiq

\section{PENDAHULUAN}

Beberapa negara di Dunia mengalami masalah perekonomian hal tersebut dapat dilihat dari tingkat pendapatan dan kesenjangan hidup masyarakatnya. Pembangunan perekonomian Indonesia setelah krisis ekonomi belum mencapai kearah yang diharapkan seperti belum meratanya pembangunan di beberapa daerah. Adapun alat ukur kemiskinan yaitu: metode yang digunakan untuk mengukur tingkat kemiskinan yang didasarkan pada ketidakmampuan memenuhi kebutuhan dasar yang bersifat fisik, seperti pangan dan perumahan.

Berdasarkan data yang diperoleh dari Badan Pusat Statistik (BPS) pada bulan Maret 2018 kemiskinan di Indonesia mencapai 25,95 juta atau 9,82 \% dari total penduduk. Jumlah itu ternyata turun sebesar 633,2 ribu orang jika dibandingkan dengan periode September 2017 yang mencapai 26,58 juta orang atau $10,12 \%$ dari total penduduk.

Kota Surabaya merupakan salah satu kota terbesar kedua di Indonesia

\footnotetext{
${ }^{1}$ Jurnal ini merupakan bagian dari skripsi Muhammad Afthon Ashar, NIM: 041211433049, yang diuji pada tanggal 18 April 2019.
} 
Ashar, et al/Jurnal Ekonomi Syariah Teori dan Terapan Vol. 6 No. 5 Mei 2019: 1057-1071; IMPLEMENTASI METODE CIBEST (CENTER OF ISLAMIC BUSINESS AND ECONOMIC STUDIES) DALAM MENGUKUR PERAN ZAKAT PRODUKTIF TERHADAP PEMBERDAYAAN MUSTAHIQ DI LEMBAGA YAYASAN DANA SOSIAL ALFALAH (YDSF) SURABAYA

setelah Jakarta. Permasalahan perekonomian di kota surabaya yang kurang merata membuat terjadinya kemiskinan di beberapa daerah. Pada tahun 2017, Garis Kemiskinan Kota Surabaya berada pada level Rp. 473.365 per kapita per bulan atau meningkat sekitar Rp. 36.000 dibandingkan Garis Kemiskinan tahun 2016. Walaupun terjadi kenaikan Garis Kemiskinan jumlah penduduk miskkin tahun 2017 di Kota Surabaya justru berkurang 6 ribu lebih menjadi hampir 155 ribu orang (5,39\%) dibanding kondisi tahun 2016 yang mencapai 161 ribu orang $(5,63)$

Permasalahan keiskinan merupakan masalah ekonnomi yang sangat erat kaitannya dengan dimensi sosial. Zakat memiliki definisi akar kata yang mengacu pada makna ath-thaharah yang berarti pertambahan. Irfan Syuqi Beiq (2009) menyatakan bahwa "zakat, infak, dan sedekah adalah salah satu instrumen kebijakan atau instrumen alternatif yang diharapkan menjadi solusi terhadap masalah kemiskinan dan masalah-masalah lainnya". Zakat diharapkan dapat menjadi instrumen alternatif, untuk mengantisipasi dampak kemiskinan global.

Pengukuran dampak zakat produktif dalam mengurangi kemiskinan umumnya masih terbatas pada material. Oleh karena itu, dibutuhkan suatu model yang mampu mengukur aspek material dan juga aspek spiritual secara bersamaan. CIBEST (CENTER OF ISLAMIC BUSINESS AND ECONOMIC STUDIES) merupakan metodde baru yang mengukur kemiskinan dari prespektif Islam dengan menyelaraskan aspek material dan spiritual.

\section{LANDASAN TEORI \\ Zakat}

Zakat merupakan pengambilan dari harta tertentu, yang didasarkan pada tata cara tertentu dan diberikan kepada orangorang yang membutuhkan. Zakat merupakan jumlah tertentu yang telah ditentukan oleh Allah SWT untuk yang berhak terhadap zakat sebagaimana ditentukan dalam Al-Quran.

Zakat memiliki unsur-unsur yang jika dirumuskan oleh Hamzah (2008:44), zakat memiliki unsur-unsur yang meliputi:

1. Sebagai suatu kewajiban bagi agama Islam.

2. Bersifat material, dalam islam dibedakan menjadi dua yaitu (1) zakat Fitri yang diberikan kepada setiap jiwa yang beragama Islam dan seluruh lapisan umur sebelum dilaksanakannya shalat Idul Fitri, (2) zakat harta merupakan kewajiban yang bersifat material untuk seluruh pendapatan.

3. Memiliki syarat yaitu mencakup kepemilikan harta dalam satu tahun yang disebut dengan haul, jumlah harta dalam bentuk minimal yang disebut nisab.

4. Diberikan kepada kelompok mustahiq, yaitu kelompok penerima zakat hanya berjumlah delapan kelompok. 
Ashar, et al/Jurnal Ekonomi Syariah Teori dan Terapan Vol. 6 No. 5 Mei 2019: 1057-1071; IMPLEMENTASI METODE CIBEST (CENTER OF ISLAMIC BUSINESS AND ECONOMIC STUDIES) DALAM MENGUKUR PERAN ZAKAT PRODUKTIF TERHADAP PEMBERDAYAAN MUSTAHIQ DI LEMBAGA YAYASAN DANA SOSIAL ALFALAH (YDSF) SURABAYA

\section{Zakat Produktif}

Zakat produktif adalah kegiatan pengelolaan dana zakat dengan cara memberikan bantuan berupa dana yang diperuntukan bagi kegiatan usaha produktif, sehingga kedepannya akan memberikan dampak positif bagi para mustahiq, serta dapat memberikan peluang kerja. Salah satu contoh pendayagunaan zakat produktif seperti diberikannya modal kerja, pelatihan, serta pendampingan dalam usaha, agar dana yang diberikan dapat memperoleh hasil yang maksimal dan terjadi kemandirian bagi mustahiq.Zakat akan berguna dan berhasil diberikan pada mustahiq apabila pendistribusian zakat sesuai dengan pengelolaan yang baik, hendaknya pengelolaan zakat menurut Asnaini (2008:136) zakat produktif perlu diiringi dengan:

1. Pengelolaan lembaga zakat dengan managemen modern dan tradisional

2. Adanya 'amil yang jujur, adil, dan bertanggung jawab

3. Pengumpulan zakat secara maksimal

4. Kebijaksanaan pemerintah (UU) yang mengatur tentang pengelolaan zakat secara jelas, adil, dan bijaksana

5. Hendaknya para mustahia, muzakki, dan 'amil menjadikan zakat sebagai daya dorong pertumbuhan ekonomi rakyat.

\section{Center of Islamic Business and Economic Studies (CIBEST)}

Berdasarkan definisi kemiskinan materiil, priritual, dan kemiskinan absolut maka dapat dibentuk dengan kuadran CIBEST (Center of Islamic Business and Economic Studies-IPB).Kuadran CIBEST terdiri dari empat kuadran sebagaimana dapat dilihat pada gambar dibawah ini.

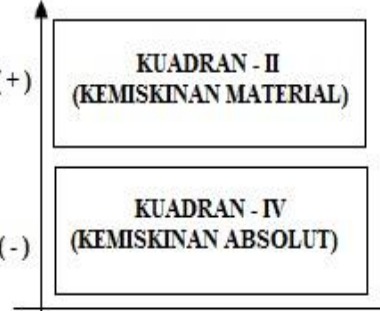

$(-)$

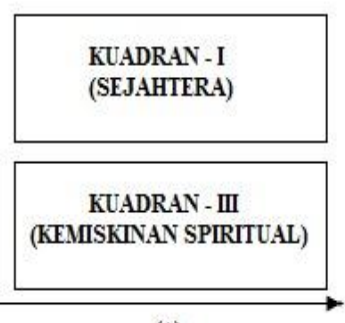

$(+)$
GARIS KEMISKINAN MATERLAL

\section{Gambar 1.}

CIBEST Kuadran

Sumber : Beik dan Arsyanti. 2016. Ekonomi Pembangunan Syariah edisi revisi.Hal. 76

Pembagian kuadran didasarkan pada kemampuan rumah tangga untuk memenuhi kebutuhan materiil dan spritual. Digunakannya rumah tangga sebagai unit of analysis karena Islam memandang bahwa unit terkecil dalam masyarakat adalah kelvarga atau rumah tangga.Karena itu, dalam melihat tingkat kemiskinan, maka rumah tangga ini harus dilihat sebagai satu kesatuan yang utuh.

\section{Indeks Kemiskinan Islami: Model CIBEST}

Salah satu alat ukur yang tengah dikembangan adalah Cibest Model atau indeks CIBEST. Pengembangan indeks ini didasarkan pada kuadran CIBEST yang dibagi menjadi empat area, yaitu area kesejahteraan, kemiskinan spiritual, kemiskinan materiil, dan kemiskinan absolut.Indeks CIBEST ini mencoba menghitung jumlah penduduk yang 
Ashar, et al/Jurnal Ekonomi Syariah Teori dan Terapan Vol. 6 No. 5 Mei 2019: 1057-1071; IMPLEMENTASI METODE CIBEST (CENTER OF ISLAMIC BUSINESS AND ECONOMIC STUDIES) DALAM MENGUKUR PERAN ZAKAT PRODUKTIF TERHADAP PEMBERDAYAAN MUSTAHIQ DI LEMBAGA YAYASAN DANA SOSIAL ALFALAH (YDSF) SURABAYA

berada di masing-masing kuadran dan implikasinya terhadap kebijakan pemerintah.Fokus kebutuhan yang perlu dihitung adalah kebutuhan materiil dan spiritual.

Unit analisis dari indeks CIBEST ini adalah rumah tangga atau keluarga. Hal ini dikarenakan keluarga atau rumah tangga harus dipandang sebagai satu kesatuan yang utuh, sama seperti konseo yang dikembangkan BKKBN. Dalam konsep CIBEST, rumah tangga atau keluarga ini dibagi menjadi enam sub kelompok, yaitu kepala rumah tangga atau keluarga, orang dewasa bekerja, orang dewasa tidak bekerja usia >18 tahun, remaja usia 14-18 tahun, anak-anak usia 7-13 tahun, dan anak-anak berusia 6 tahun atau kurang dari 6 tahun. Indeks CIBEST ini terdiri dari empat indeks, yaitu indeks kesejahteraan, indeks kemiskinan materiil, indeks kemiskinan spiritual, dan indeks kemiskinan absolut.

Namun dalam penelitian ini, skor kebutuhan spiritual diperoleh dengan menggunakan pendekatan presepsi kepala keluarga.Kepala keluarga dapat menggambarkan masing-masing variabel indikator kebutuhan spiritual dalam keluarga tersebut.Hal ini dikarenakan keterbatasan waktu dan kondisi keluarga di lapangan.

$$
\text { Garis kemiskinan spiritual }
$$
nilainya adalah sama dengan tiga. Hal ini didasarkan pada argumentasi bahwa kemiskinan spiritual terjadi ketika seseorang atau dalam satu keluarga tidak melaksanakan ibadah wajib secara rutin, atau dianggap ibadah menjadi urusan pribadi anggota keluarga, atau masyarakat tidak perlu diatur dengan baik.Untuk menghitung jumlah keluarga yang miskin secara spiritual, langkah pertama yang dilakukan yaitu dengan menghitung skor spiritual anggota keluarga, kemudian menghitung skor spiritual keluarga secara rata-rata, dan menghitung spiritual seluruh anggota keluarga yang diobservasi.

Skor ini didapat melalui survei yang dilakukan kepada keluarga secara langsung. Khusus variabel nomor 4 dan 5 , skor untuk lingkungan keluarga dan kebijakan pemerintah didasarkan pada pendapat pribadi anggota keluarga yang disurvei terhadap kondisi lingkungan keluarga mereka dan kebijakan pemerintah yang mereka rasakan terkait pelaksanaan ibadah.

\section{METODOLOGI PENELITIAN}

\section{Pendekatan Penelitian}

Pendekatan penelitian ini menggunakan metode kuantitatif eksploratori (eksploratif). Menurut Sugiyono (2009:7), penelitian kuantitatif dinamakan metode tradisional karena metode ini cukup lama digunakan sehingga sudah mentradisi sebagai metode untuk penelitian. Metode penelitian kuantitatif berlandaskan positivisme, digunakan untuk meneliti populasi tertentu, pengumpulan dan menggunakan instrumen penelitian, analisis data bersifat kuantitatif/statistik, dengan tujuan untuk menguji hipotesis 
Ashar, et al/Jurnal Ekonomi Syariah Teori dan Terapan Vol. 6 No. 5 Mei 2019: 1057-1071; IMPLEMENTASI METODE CIBEST (CENTER OF ISLAMIC BUSINESS AND ECONOMIC STUDIES) DALAM MENGUKUR PERAN ZAKAT PRODUKTIF TERHADAP PEMBERDAYAAN MUSTAHIQ DI LEMBAGA YAYASAN DANA SOSIAL ALFALAH (YDSF) SURABAYA

yang telah ditetapkan (Sugiyono, 2009:8). Menurut Arikunto (2002) dalam Anshori dan Iswati (2009:15), banyak dituntut menggunakan angka, mulai dari pengumpulan data, serta penampilan hasilnya.

\section{Identifikasi Variabel}

Menurut Sugiyono

(2009:38)

menyimpulkan bahwa: "variabel adalah suatu atribut atau sifat atau nilai dari orang, obyek, atau kegiatan yang mempunyai variasi tertentu yang ditetapkan oleh peneliti untuk dipelajari dan kemudian ditarik kesimpulannya". Pada penelitian ini akan dirumuskan empat kuadran yang didasarkan pada area kesejahteraan, kebutuhan spiritual (skala likert), kemiskinan materiil, dan kemiskinan absolut mustahia. Variabel yang akan diteliti adalah pendapatan rumah tangga mustahiq sebelum dan sesudah adanya bantuan zakat produktif yang dilihat berdasarkan materi dan spiritual mustahia yang nantinya akan dikaji berdasarkan indeks kemiskinan islami CIBEST.

\section{Definisi Operasional Variabel}

Definisi operasional adalah suatu definisi yang diberikan kepada suatu variabel atau kontrak dengan cara memberikan arti, atau menspesifikasi kegiatan, ataupun memberikan suatu operasional yang diperlukan untuk mengukur variabel atau konstrak tersebut (Anshori dan Iswati, 2009:60). Penelitian ini bertujuan untuk menggali faktor yang mempengaruhi keputusan untuk menunaikan wakaf uang di Surabaya, untuk menentukan indikator dari faktor yang menyebabkan keputusan untuk menunaikan wakaf uang di Surabaya diperoleh dari hasil proses pengngambilan data melalui wawancara tertulis dalam pre eliminary test. Indikator tersebut akan diukur menggunakan skala likert yang telah dimodifikasi, yaitu jawaban tengah dihilangkan. Rentang skala dalam pengukuran ini dimulai dari angka 1 sampai 4 yaitu sangat tidak setuju (1), tidak setuju (2), setuju (3), dan sangat setuju (4).

\section{Jenis dan Sumber Data}

Jenis dan sumber data yang digunakan dalam penelitian ini merupakan faktor penting dalam pertimbangan penentuan metode pengumpulan data. Jenis dan sumber data yang digunakan pada penelitian ini yaitu data primer dan sekunder. Data primer yaitu data yang diperoleh langsung dari responden melalui pembagian kuisioner. Data sekunder dalam penelitian ini yang digunakan diperoleh melalui internet, jurnal, dan literatur-literatur lainnya yang berhubungan dengan penelitian ini.

\section{Prosedur Pengumpulan Data}

\section{Populasi dan Sampel}

Populasi merupakan himpunan individu yang memiliki ciri-ciri atau karakteristik yang sama. Menurut Sugiyono (2017:80), definisi populasi adalah sebagai berikut: "populasi adalah wilayah generalisasi yang terdiri atas; objek/ subyek yang mempunyai kualitas dan karakteristik tertentu yang ditetapkan oleh peneliti untuk pelajari dan kemudian di tarik 
Ashar, et al/Jurnal Ekonomi Syariah Teori dan Terapan Vol. 6 No. 5 Mei 2019: 1057-1071; IMPLEMENTASI METODE CIBEST (CENTER OF ISLAMIC BUSINESS AND ECONOMIC STUDIES) DALAM MENGUKUR PERAN ZAKAT PRODUKTIF TERHADAP PEMBERDAYAAN MUSTAHIQ DI LEMBAGA YAYASAN DANA SOSIAL ALFALAH (YDSF) SURABAYA

kesimpulannya". Populasi dalam penelitian ini adalah mustahiq yang diberikan dana bantuan zakat produktif yang terdapat di lembaga Yayasan Dana Al-Falah di Surabaya . Jumlah mustahiq yang mendapat bantuan zakat berjumlah 8 rumah tangga.

\section{Metode Pengambilan Sampel}

Pada penelitian ini menggunakan Purposive Sampling, dimana pada teknik ini digunakan oleh peneliti karena penelliti memiliki pertimbangan-pertimbangan tertentu dalam pengambilan datanya. Menurut Sugiyono (2017:85),purposive sampling adalah sebagai berikut: "purposive sampling adalah teknik penentuan sampel dengan pertimbangan tertentu".

\section{Teknik Pengumpulan Data}

Penelitian ini menggunakan prosedur pengumpulan data yang dilakukan dengan cara pre eliminary test, studi kepustakaan, studi lapangan.

\section{Teknik Analisis Data}

Penelitian ini menggunakan teknik analisis metode CIBEST (Center of Islamic Bussiness and Economic Studies. Alat ukur kemiskinan yang digunakan pada dasar indeks kemiskinan Islami. Indeks CIBEST dikembangkan oleh Irfan Syauqi Beik dan Dwi Arisyanti pada tahun 2014. Rumah tangga dijadikan sebagai unit analisis karena Islam memandang unit terkecil dalam masyarakat adalah rumah tangga.

\section{Indeks Kesejahteraan}

Indeks kesejahteraan yang dikembangkan oleh CIBEST berupaya untuk menggambarkan sebaran rumah tangga yang termasuk dalam kategori sejahtera pada kuadran I. Sejahtera dalam konteks ini adalah rumah tangga yang berkecukupan secara material dan spiritual. Indeks kesejahteraan didapatkan dari rasio jumlah rumah tangga sejahtera dengan jumlah populasi rumah tangga yang diobservasi. Rumus indeks kesejahteraan berdasarkan Beik dan Arsyanti (2016:90) adalah sebagai berikut: $W=\frac{w}{N}$

Dimana:

$\mathrm{W}=$ indeks kesejahteraan; $0 \leq W \leq 1$

$W=$ jumlah keluarga sejahteraa (kaya secara materiil dan spiritual)

$\mathrm{N}=$ jumlah populasi (jumlah keluarga yang diobservasi)

Rumus kebutuhan materiil minimal yang harus dipenuhi oleh suatu keluarga adalah sebagaimana yang ditunjukkan oleh Beik dan Arsyanti (2016:91) seperti berikut:

$\mathrm{MV}=\sum_{\mathrm{i}=1}^{\mathrm{n}} \mathrm{PiMi}$

Dimana:

$M V$ = standar minimal kebutuhan materiil yang harus dipenuhi sekeluarga (RP atau mata vang lain) atau disebut juga garis kemiskinan

$\mathrm{Pi} \quad=$ harga barang dan jasa (Rp atau mata vang lain)

Mi = jumlah minimal barang dan jasa yang dibutuhkan

\section{Spriritual Value (SV)}

Spiritual Value (SV) didasarkan pada kebutuhan spiritualdan formulaformula penentuan skor spiritual. Indikator 
Ashar, et al/Jurnal Ekonomi Syariah Teori dan Terapan Vol. 6 No. 5 Mei 2019: 1057-1071; IMPLEMENTASI METODE CIBEST (CENTER OF ISLAMIC BUSINESS AND ECONOMIC STUDIES) DALAM MENGUKUR PERAN ZAKAT PRODUKTIF TERHADAP PEMBERDAYAAN MUSTAHIQ DI LEMBAGA YAYASAN DANA SOSIAL ALFALAH (YDSF) SURABAYA

kebutuhan spiritual rumah tangga, Beik dan Arsyanti (2016) yaitu: "standar pemenuhan lima variabel yaitu ibadah shalat, zakat, dan puasa dikatakan terpenuhi bagi suatu rumah tangga apabila minimal menjalankan ibadah wajib seperti sholat lima waktu, puasa ramadhan dan membayar zakat minimal satu kali setahun". Sedangkan variabel lingkungan rumah tangga dan kebijakan pemerintah didasarkan pada presepsi pribadi masingmasing anggota rumah tangga dan kebijakan pemerintah yang dirasakan dalam hal pemenuhan kebutuhan spiritual. Untuk menilai skor pada masing-masing variabel digunakan skala Likert antara 1-5.

perhitungan skor spiritual individu anggota rumah tangga atau keluarga berdasarkan Beik dan Arsyanti (2016:94) didasarkan pada rumus berikut ini:

$\mathrm{Hi}=\frac{V p i+V f i+V z i+V h i+V g i}{5}$

Dimana:

$\mathrm{Hi}=$ skor aktual anggota keluarga ke- $\mathrm{i}$

$\mathrm{Vpi} \quad=$ skor shalat anggota keluarga ke-i

$\mathrm{Vfi}=$ skor puasa anggota keluarga ke-i

Vzi $=$ skor zakat dan infak anggota keluarga ke-i

Vhi = skor lingkungan keluarga menurut anggota kelvarga ke-i

Vgi $=$ skor kebijakan pemerintah menurut anggota keluarga ke-i

Dari hasil skor individu anggota keluarga ini, kemudian dapat ditentukan skor spiritual rumah tangga atau keluarga, dengan menjumlahkan skor seluruh anggota keluarga dan membaginya dengan jumlah anggota kelvarga. Rumusnya menurut Beik dan Arsyanti (2016:95) sebagai berikut ini:

$\mathrm{SH}=\sum_{\mathrm{h}=1}^{\mathrm{n}}=\frac{\mathrm{H} 1+\mathrm{H} 2+\cdots . .+\mathrm{Hn}}{\mathrm{MH}}$

Dimana:

$\mathrm{SH}=$ skor rata-rata kondisi spiritual keluarga $\mathrm{H}_{\mathrm{h}}=$ skor kondisi spiritual anggota keluarga ke-h

$\mathrm{MH}=$ jumlah anggota keluarga

Dari skor SH yang mencerminkan nilai spiritualitas suatu keluarga, maka dapat dihitung beberapa nilai spiritualitas keluarga-keluarga dalam suatu wilayah dan bahkan suatu negara. Rumusnya seperti pada Beik dan Arsyanti (2016:95) sebagai berikut:

$\mathrm{SS}=\sum_{\mathrm{k}=1}^{\mathrm{n}} \frac{\mathrm{SHK}}{\mathrm{N}}$

Dimana:

SS = skor rata-rata kondisi spiritual keseluruhan keluarga yang diamati SHK = skor kondisi spiritual keluarga ke-k

$\mathrm{N} \quad=$ jumlah keseluruhan keluarga yang diamati disuatu wilayah atau negara

\section{Indeks Kemiskinan Material}

Kemiskinan material (Pm) ini berguna untuk melihat sebaran rumah tangga yang berada pada kuadran II yang termasuk pada kategori miskin material. Indeks kemiskinan II didapatkan melalui perbandingan antara jumlah rumah tangga yang miskin secara material tetapi kaya spiritual dengan jumlah populasi total keluarga yang diamati. Indeks kemiskinan material ini bernilai antara $0-1$. 
Ashar, et al/Jurnal Ekonomi Syariah Teori dan Terapan Vol. 6 No. 5 Mei 2019: 1057-1071; IMPLEMENTASI METODE CIBEST (CENTER OF ISLAMIC BUSINESS AND ECONOMIC STUDIES) DALAM MENGUKUR PERAN ZAKAT PRODUKTIF TERHADAP PEMBERDAYAAN MUSTAHIQ DI LEMBAGA YAYASAN DANA SOSIAL ALFALAH (YDSF) SURABAYA

Rumus untuk menghitung indeks kemiskinan materiil seperti pada Beik dan Arsyanti (2016:96) seperti berikut:

$\mathrm{Pm}=\frac{\mathrm{Mp}}{\mathrm{N}}$

Dimana:

$\mathrm{Pm} \quad=$ indeks kemiskinan materiil; $0 \leq \mathrm{Pm}$ $\leq 1$

$\mathrm{Sp}=$ jumlah keluarga miskin secara materiil namun kaya secara spiritual

$\mathrm{N}=$ jumlah populasi (total keluarga yang diamati)

\section{Indeks Kemiskinan Spiritual}

Indeks Kemiskinan Spiritual (Ps) ini berguna untuk melihat sebaran rumah tangga yang termasuk dalam kategori rumah tangg yang mengalami kemiskinan spiritual tetapi berkecukupan secara material pada kuadran III. Indeks kemiskinan spiritual merupakan rasio antara jumlah keluarga yang miskin secara spiritual tetapi berkecukupan secara material dengan jumlah populasi total keluarga yang diamati. Indeks kemiskinan material ini bernilai antara $0-1$, semakin kecil atau semakin mendekati 0 maka semakin rendah tingkat kemiskinan spiritual rumah tangga disuatu wilayah.

indeks kemiskinan spiritual pada Beik dan Arsyanti (2016:97) sebagai berikut:

$$
\mathrm{Ps}=\frac{\mathrm{Sp}}{\mathrm{N}}
$$

Dimana:

Ps $\quad=$ indeks kemiskinan spiritual; $0 \leq$ Ps $\leq$ 1

$\mathrm{Sp}=$ jumlah keluarga miskin secara spiritual namun kaya secara materiil
$\mathrm{N} \quad=$ jumlah populasi (total keluarga yang diamati)

\section{Indeks Kemiskinan Absolut}

Indeks kemiskinan absolut (Pa) berguna untuk melihat sebaran jumlah rumah tangga yang masuk kedalam kategori miskin secara material dan juga miskin secara spiritual pada kuadran IV. Indeks kemiskinan absolut merupakan rasio perbandingan antara jumlah rumah tangga yang miskin secara material dan spiritual dengan jumlah populasi total rumah tangga yang diamati. Indeks kemiskinan absolut bernilai antara 0 - 1 , semakin kecil nilai indeks kemiskinan absolut maka semakin rendah tingkat kemiskinan aboslut rumah tangga dalam suatu wilayah.

rumus untuk indeks kemiskinan absolut pada Beik dan Arsyanti (2016:97) sebagai berikut:

$\mathrm{Pa}=\frac{\mathrm{Ap}}{\mathrm{N}}$

$\mathrm{Pa} \quad=$ indeks kemiskinan absolut; $0 \leq \mathrm{Ps} \leq$ 1

$\mathrm{Sp}=$ jumlah keluarga miskin secara spiritual dan miskin secara materiil

$\mathrm{N} \quad=$ jumlah populasi (total keluarga yang diamati)

\section{PEMBAHASAN}

\section{Karakteristik Kepala Rumah Tangga Mustahiq}

Responden dalam penelitian ini berjumlah 8 penerima zakat produktif dari YDSF. Adapun keadaan umum responden Mayoritas mustahiq berjenis kelamin laki-laki dengan presentase sebesar $62,5 \%$. 
Ashar, et al/Jurnal Ekonomi Syariah Teori dan Terapan Vol. 6 No. 5 Mei 2019: 1057-1071; IMPLEMENTASI METODE CIBEST (CENTER OF ISLAMIC BUSINESS AND ECONOMIC STUDIES) DALAM MENGUKUR PERAN ZAKAT PRODUKTIF TERHADAP PEMBERDAYAAN MUSTAHIQ DI LEMBAGA YAYASAN DANA SOSIAL ALFALAH (YDSF) SURABAYA

Sedangkan mustahiq berjenis kelamin perempuan sebesar $37,5 \%$.Seluruh musahik dengan usia produktif yaitu usia 15-64 tahun sebesar $100 \%$, sedangkan mustahiq tidak ada yang berusia diatas 64 tahun. Tingkat pendidikan mustahiq SMA/ SMK yaitu sebesar 62,5\%, Mustahiq yang berpendidikan SMP sebesar 12,5\% , Mustahiq yang berpendidikan SD sebesar $25 \%$, dan Mustahiq yang tidak bersekolah sebesar 0\%. Pekerjaan Mustahiq sebagai pedagang sebesar $37,5 \%$, sebagai penjahit $12,5 \%$, sebagai kuli serabutan $12,5 \%$, sebagai tukang las $25 \%$ dan buruh pabrik $12,5 \%$.

Analisis Model CIBEST Sebelum Adanya Bantuan Dana Zakat Produktif

Responden dalam penelitian ini berjumlah 8 keluarga mustahiq. Berdasarkan analisis kuadran CIBEST yang telah dilakukan, berikut kondisi sebelum adanya program zakat produktif YDSF.

$(+)$

Garis

Kemiskinan Spiritual $(-)$

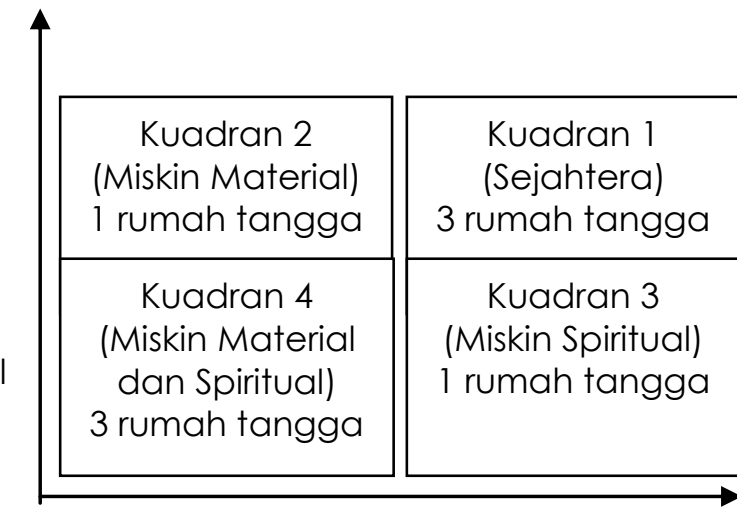

$(-)$

$(+)$

Gambar 2.

\section{Garis Kemiskinan Spiritual}

Sumber: Data Primer (2018)

Berdasarkan gambar diatas

terdapat total 8 keluarga mustahiq yang diteliti. Kuadran I adalah kategori keluarga mustahiq yang sejahtera dimana dalam kategori ini keluarga mustahia telah mampu memenuhi kebutuhan material dan spiritual. Sebelum adanya bantuan dana zakat produktif dari YDSF terdapat 3 keluarga yang termasuk dalam kategori kuadran I.

Kuadran II adalah kategori keluarga mustahiq yang miskin material, dalam kategori ini keluarga mustahiq telah mampu memenuhi kebutuhan spiritual namun belum mampu memenuhi kebutuhan material. Sebelum adanya bantuan dana zakat produktif dari YDSF terdapat 1 keluarga yang termasuk dalam kategoti miskin spiritual.

Kuadran III adalah kategori keluarga mustahiq yang miskin spiritual, dalam kategori ini keluarga mustahiq telah mampu memenuhi kebutuhan material namun belum mampu memenuhi kebutuhan spiritual. Sebelum adanya bantuan dana zakat produktif YDSF terdapat 1 keluarga yang termasuk dalam kategori miskin spiritual.

Kuadran IV adalah kategoti kelvarga miskin materi dan spiritual (absolut), dalam kategori ini keluarga mustahiq belum mampu memenuhi kebutuhan secara materi maupun spiritual. Sebelum adanya bantuan dana zakat produktif YDSF terdapat 3 keluarga yang termasuk dalam kategori absolut.

Analisis Model CIBEST Setelah Adanya Bantuan Dana Zakat Produktif 
Ashar, et al/Jurnal Ekonomi Syariah Teori dan Terapan Vol. 6 No. 5 Mei 2019: 1057-1071; IMPLEMENTASI METODE CIBEST (CENTER OF ISLAMIC BUSINESS AND ECONOMIC STUDIES) DALAM MENGUKUR PERAN ZAKAT PRODUKTIF TERHADAP PEMBERDAYAAN MUSTAHIQ DI LEMBAGA YAYASAN DANA SOSIAL ALFALAH (YDSF) SURABAYA

Responden dalam penelitian ini berjumlah 8 keluarga mustahiq. Berdasarkan analisis kuadran CIBEST yang telah dilakukan, berikut kondisi setelah adanya program zakat produktif YDSF.
$(+)$

Garis

Kemis-

kinan

Spiritual

$(-)$

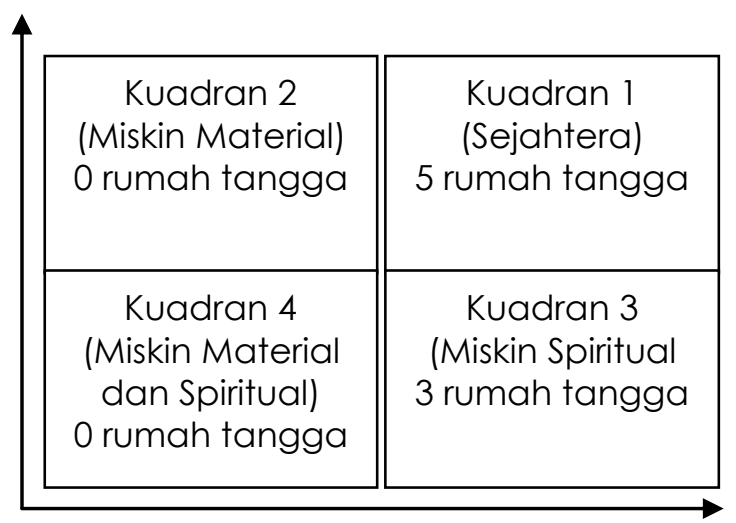

$(-)$

\section{Gambar 3.}

\section{Garis Kemiskinan Spiritual}

Sumber: Data Primer (2018)

Berdasarkan gambar di atas terdapat total 8 keluarga mustahiq yang diteliti. Kuadran I adalah kategori keluarga mustahiq yang sejahtera dimana dalam kategori ini keluarga mustahiq telah mampu memenuhi kebutuhan ntaterial dan spiritual. Setelah adanya bantuan dana zakat produktif dari YDSF teroterexist 5 keluarga yang termasuk dalam Kcengseri kuadran I. inan

Kuadran II adalah kategori kmichtroged mustahiq yang miskin material, dalam kategori ini keluarga mustahiq telah mampu memenuhi kebutuhan spiritual namun belum mampu memenuhi kebutuhan material. Setelah adanya bantuan dana zakat produktif dari YDSF tidak ada keluarga yang termasuk dalam kuadran II.

$$
\text { Kuadran III adalah kategori }
$$
keluarga mustahiq yang miskin spiritual, dalam kategori ini keluarga mustahiq telah mampu memenuhi kebutuhan material namun belum mampu memenuhi kebutuhan spiritual. Setelah adanya bantuan dana zakat produktif YDSF terdapat 3 keluarga yang termasuk dalam kategori miskin spiritual.

Kuadran IV adalah kategoti keluarga miskin materi dan spiritual (absolut), dalam kategori ini keluarga mustahiq belum mampu memenuhi kebutuhan secara materi maupun spiritual. Setelah adanya bantuan dana zakat produktif YDSF terdapat tidak ada keluarga yang termasuk dalam kuadran IV.

\section{Analisis Model CIBEST Rumah Tangga}

Mustahiq YDSF Sebelum dan Setelah Adanya Bantuan Dana Zakat Produktif YYayasan Dana Sosial Al-Falah Surabaya

\begin{tabular}{|c|c|c|c|}
\hline \multicolumn{2}{|c|}{$\begin{array}{c}\text { Kuadran } 2 \\
\text { Miskin Material }\end{array}$} & \multicolumn{2}{|c|}{$\begin{array}{l}\text { Kuadran } 1 \\
\text { Sejahtera }\end{array}$} \\
\hline $\begin{array}{l}\text { Sebelum } \\
\text { Bantuan } \\
\text { Dana } \\
1\end{array}$ & $\begin{array}{l}\text { Setelah } \\
\text { Bantuan } \\
\text { Dana } \\
0\end{array}$ & $\begin{array}{l}\text { Sebelum } \\
\text { Bantuan } \\
\text { Dana } \\
3\end{array}$ & $\begin{array}{l}\text { Setelah } \\
\text { Bantuan } \\
\text { Dana } \\
5\end{array}$ \\
\hline \multicolumn{2}{|c|}{$\begin{array}{c}\text { Kuadran } 4 \\
\text { Miskin Material } \\
\text { dan Spiritual }\end{array}$} & \multicolumn{2}{|c|}{$\begin{array}{c}\text { Kuadran } 3 \\
\text { Miskin Spiritual }\end{array}$} \\
\hline $\begin{array}{l}\text { Sebelum } \\
\text { Bantuan } \\
\text { Dana } \\
3\end{array}$ & $\begin{array}{l}\text { Setelah } \\
\text { Bantuan } \\
\text { Dana } \\
0\end{array}$ & $\begin{array}{l}\text { Sebelum } \\
\text { Bantuan } \\
\text { Dana } \\
3\end{array}$ & $\begin{array}{l}\text { Setelah } \\
\text { Bantuan } \\
\text { Dana } \\
0\end{array}$ \\
\hline
\end{tabular}

$(+)$

Gambar 4.

Garis Kemiskinan Spiritual

Sumber: Data Primer (2018) 
Ashar, et al/Jurnal Ekonomi Syariah Teori dan Terapan Vol. 6 No. 5 Mei 2019: 1057-1071; IMPLEMENTASI METODE CIBEST (CENTER OF ISLAMIC BUSINESS AND ECONOMIC STUDIES) DALAM MENGUKUR PERAN ZAKAT PRODUKTIF TERHADAP PEMBERDAYAAN MUSTAHIQ DI LEMBAGA YAYASAN DANA SOSIAL ALFALAH (YDSF) SURABAYA

Berdasakan gambar di atas terlihat bahwa perubahan dari masing-masing kuadran. Kuadran I adalah kategori keluarga mustahiq yang sejahtera dimana dalam kategori ini keluarga mustahiq telah mampu memenuhi kebutuhan material dan spiritual. Sebelum adanya bantuan dana zakat produktif dari YDSF terdapat 3 keluarga yang termasuk dalam kategori kuadran I. Setelah adanya bantuan dana zakat produktif YDSF jumlah keluarga mustahiq kategori sejahtera meningkat menjadi 5 keluarga.

Kuadran II adalah kategori keluarga mustahiq yang miskin material, dalam kategori ini keluarga mustahiq telah mampu memenuhi kebutuhan spiritual namun belum mampu memenuhi kebutuhan material. Sebelum adanya bantuan dana zakat produktif dari YDSF terdapat 1 keluarga yang termasuk dalam kategoti miskin spiritual. Namun setelah adanya bantuan dana zakat produktif YDSF tidak ada keluarga mustahiq kategori miskin material tetap.

Kuadran III adalah kategori keluarga mustahiq yang miskin spiritual, dalam kategori ini keluarga mustahiq telah mampu memenuhi kebutuhan material namun belum mampu memenuhi kebutuhan spiritual. Sebelum adanya bantuan dana zakat produktif YDSF terdapat 1 keluarga yang termasuk dalam kategori miskin spiritual. Setelah adanya bantuan dana zakat produktif YDSF jumlahkeluarga mustahiq kategori miskin spiritual sama seperti sebelumnya yaitu terdapat 3 keluarga.

Kuadran IV adalah kategoti kelvarga miskin materi dan spiritual (absolut), dalam kategori ini keluarga mustahiq belum mampu memenuhi kebutuhan secara materi maupun spiritual. Sebelum adanya bantuan dana zakat produktif YDSF terdapat 3 keluarga yang termasuk dalam kategori absolut. Namun setelah adanya bantuan dana zakat produktif YDSF jumlah keluarga mustahiq kategori absolut menurun menjadi tidak ada.

Secara umum adanya program bantuan dana zakat produktif YDSF mampu meningkatkan keluarga mustahia menjadi sejahtera, namun masih terdapat 3 keluarga yang masih menempati kuadran III yaitu muskin spiritual.

\section{Analisis Indeks Kemiskinan Islami Keluarga} Mustahiq

Indeks kesejahteraan keluarga mustahiq sebelum adanya program zakat produktif YDSF adalah 0,375. Setelah adanya program penyaluran zakat produktif YDSF, indeks kesejahteraan berubah menjadi 0,625. Hal ini berarti program penyaluran manfaat zakat produktif dapat meningkatkan indeks kesejahteraan sebesar $27 \%$.

Indeks kemiskinan material keluarga mustahiq sebelum adanya program zakat produktif YDSF adalah 0,125. Setelah adanya program penyaluran zkat produktif YDSF, indeks kemisninan material berubah menjadi 0 . Hal ini berarti program 
Ashar, et al/Jurnal Ekonomi Syariah Teori dan Terapan Vol. 6 No. 5 Mei 2019: 1057-1071; IMPLEMENTASI METODE CIBEST (CENTER OF ISLAMIC BUSINESS AND ECONOMIC STUDIES) DALAM MENGUKUR PERAN ZAKAT PRODUKTIF TERHADAP PEMBERDAYAAN MUSTAHIQ DI LEMBAGA YAYASAN DANA SOSIAL ALFALAH (YDSF) SURABAYA

penyaluran zakat produktif dapat meningkatkan indeks kemiskinan material sebesar $100 \%$.

Indeks kemiskinan spiritual keluarga mustahiq sebelum adanya program zakat produktif YDSF adalah 0,125. Setelah adanya program penyaluran zakat produktif YDSF, indeks kemiskinan spiritual adalah tetap yaitu 0,357. Hal ini berarti program penyaluran zakat produktif tidak menutunkan indeks kemiskinan spiritual sebesar $24 \%$.

Indeks Kemiskinan absolut keluarga mustahiq sebelum adanya program zakat produktif YDSF adalah 0,357. Setelah adanya program penyaluran zakat produktif YDSF, indeks kemisninan berubah menjadi 0 . Hal ini berarti program penyaluran manfaat zakat produktif dapat meningkatkan indeks kemiskinan absolut sebesar $100 \%$.

\section{Analisis Variabel Spiritual dalam Lingkup Individu}

Responden analisis variabel spiritual dalam lingkup individu ini terdiri dari 5 responden KK laki-laki dan 3 KK Perempuan. Terlihat bahwa sebelum dan sesudah adanya program penyaluran zakat produktif dari YDSF terdapat KK(L), KK (P), AK1, AK6, dan AK7 tidak mengalami pengingkatan dari sebelum mengikuti progran sampai setelah mengikuti program. Sedangkan untuk AK2, AK3, AK4, dan AK5 mengalami peningkatan dari sebelum mengikuti program sampai setelah mengikuti program. Adapun standar masing-masing pemenuhan kebutuhan dasar adalah SV=3

Dari sisi skor puasa dan sholat yang berada dibawah garis kemiskinan atau sama dengan garis kemiskinan yaitu $S V=3$ yang terdapat pada tabel 4.4 terdapat 0 $\mathrm{KK}(\mathrm{L}), 1 \mathrm{KK}(\mathrm{P}), 4 \mathrm{AK} 1,4 \mathrm{AK} 2,4 \mathrm{AK} 3$, dan 2 AK4, 1 AK5, 1 AK6, dan 1 AK7 yang memiliki skor puasa di bawah garis kemiskinan atau sama dengan garis kemiskinan spiritual. Setelah adanya program penyaluran zakat produktif YDSF terdapat $0 \mathrm{KK}(\mathrm{L}), 1 \mathrm{KK}(\mathrm{P}), 4$ AK1, 4 AK2, 4 AK3,dan 2 AK4, 1 AK5, 1 AK6, dan 1 AK7. Hal ini mengindikasikan bahwa tidak terdapat perubahan pada skor puasa sebelum dan sesudah mendapatkan dana bantuan zakat produktif YDSF.

Zakat dan Infaq

Adapun standar ketiga dalam pemenuhan kebutuhan dasar spiritual adalah Zakat dan Infaq sehingga Zakat dan Infaq dimasukkan dalam salah satu variabel kebutuhan spiritual. Standar yang digunakan pada variabel Zakat dan Infaq untuk keluarga adalah SV=3. Analisis Zakat dan Infaq dalam lingkup individu sebelum adanya program penyaluran zakat produktif $5 \mathrm{KK}(\mathrm{L}), 3 \mathrm{KK}(\mathrm{P}), 5$ AK1, 1 AK2, 1 AK3, 0 AK4, 0 AK5, 0 AK6, dan 0 AK7 yang memiliki skor zakat dan infaq di atas garis kemiskinan spiritual. Setelah adanya program penyaluran manfaat zakat produktif YDSF terdapat produktif $5 \mathrm{KK}(\mathrm{L}), 3$ KK(P), 5 AK1, 1 AK2, 1 AK3, 0 AK4, 0 AK5, 0 AK6, dan 0 AK7 yang memiliki skor zakat dan infaq di atas garis kemiskinan spiritual. 
Ashar, et al/Jurnal Ekonomi Syariah Teori dan Terapan Vol. 6 No. 5 Mei 2019: 1057-1071; IMPLEMENTASI METODE CIBEST (CENTER OF ISLAMIC BUSINESS AND ECONOMIC STUDIES) DALAM MENGUKUR PERAN ZAKAT PRODUKTIF TERHADAP PEMBERDAYAAN MUSTAHIQ DI LEMBAGA YAYASAN DANA SOSIAL ALFALAH (YDSF) SURABAYA

Dari sisi skor zakat dan infaq yang berada dibawah garis kemiskinan atau sama dengan garis kemiskinan yaitu $S V=3$ yang terdapat pada tabel 4.5 terdapat 0 $K K(L), 0$ KK(P), 3 AK1, 7 AK2, 5 AK3,dan 2 AK4, 1 AK5, 1 AK6, dan 1 AK7 yang memiliki skor zakat dan infaq di bawah garis kemiskinan atau sama dengan garis kemiskinan spiritual. Setelah adanya program penyaluran zakat produktif YDSF 0 KK(L), 0 KK(P), 3 AK1, 7 AK2, 5 AK3,dan 2 AK4, 1 AK5, 1 AK6, dan 1 AK7. Hal ini mengindikasikan bahwa tidak terdapat perubahan pada skor zakat dan infaq sebelum dan sesudah mendapatkan dana bantuan zakat produktif YDSF.

Lingkungan Keluarga

Adapun standar keempat dalam pemenuhan kebutuhan dasar spiritual adalah Lingkungan Keluarga sehingga Lingkungan Keluarga dimasukkan dalam salah satu variabel kebutuhan spiritual. Standar yang digunakan pada variabel Zakat dan Infaq untuk keluarga adalah $S V=3$. Lingkungan Keluarga dalam lingkup individu sebelum adanya program penyaluran zakat produktif $5 \mathrm{KK}(\mathrm{L}), 3 \mathrm{KK}(\mathrm{P})$, 4 AK1, 1 AK2, 0 AK3, 0 AK4, 0 AK5, 0 AK6, dan 0 AK7 yang memiliki skor lingkungan kelvarga di atas garis kemiskinan spiritual. Setelah adanya program penyaluran manfaat zakat produktif YDSF terdapat produktif $5 \mathrm{KK}(\mathrm{L}), 3 \mathrm{KK}(\mathrm{P}), 4 \mathrm{AK} 1,1$ AK2, 0 AK3, 0 AK4, 0 AK5, 0 AK6, dan 0 AK7 yang memiliki skor lingkungan keluarga di atas garis kemiskinan spiritual.
Dari sisi skor lingkungan keluarga yang berada dibawah garis kemiskinan atau sama dengan garis kemiskinan yaitu $S V=3$ yang terdapat pada tabel 4.6 terdapat 0 KK(L), 0 KK(P), 4 AK1, 7 AK2, 6 AK3,dan 4 AK4, 2 AK5, 1 AK6, dan 1 AK7 yang memiliki skor lingkungan keluarga di bawah garis kemiskinan atau sama dengan garis kemiskinan spiritual. Setelah adanya program penyaluran zakat produktif YDSF 0 $\mathrm{KK}(\mathrm{L}), 0 \mathrm{KK}(\mathrm{P}), 4$ AK1, 7 AK2, 6 AK3, dan 4 AK4, 2 AK5, 1 AK6, dan 1 AK7. Hal ini mengindikasikan bahwa tidak terdapat perubahan pada skor lingkungan keluarga sebelum dan sesudah mendapatkan dana bantuan zakat produktif YDSF.

Kebijakan Pemerintah

Adapun standar kelima dalam pemenuhan kebutuhan dasar spiritual adalah Kebijakan Pemerintah sehingga Kebijakan Pemerintah dimasukkan dalam salah satu variabel kebutuhan spiritual. Standar yang digunakan pada variabel Kebijakan Pemerintah untuk keluarga adalah SV=3. Kebijakan Pemerintah dalam lingkup individu sebelum adanya program penyaluran zakat produktif $5 \mathrm{KK}(\mathrm{L}), 3 \mathrm{KK}(\mathrm{P})$, 5 AK1, 0 AK2, 0 AK3, 0 AK4, 0 AK5, 0 AK6, dan 0 AK7 yang memiliki skor kebijakan pemerintah di atas garis kemiskinan spiritual. Setelah adanya program penyaluran manfaat zakat produktif YDSF terdapat produktif 5 KK(L), 3 KK(P), 5 AK 1, 1 AK2, 0 AK3, 0 AK4, 0 AK5, 0 AK6, dan 0 AK7 yang memiliki skor lingkungan keluarga di atas garis kemiskinan spiritual.Dari sisi skor kebijakan pemerintah yang berada 
Ashar, et al/Jurnal Ekonomi Syariah Teori dan Terapan Vol. 6 No. 5 Mei 2019: 1057-1071; IMPLEMENTASI METODE CIBEST (CENTER OF ISLAMIC BUSINESS AND ECONOMIC STUDIES) DALAM MENGUKUR PERAN ZAKAT PRODUKTIF TERHADAP PEMBERDAYAAN MUSTAHIQ DI LEMBAGA YAYASAN DANA SOSIAL ALFALAH (YDSF) SURABAYA

dibawah garis kemiskinan atau sama dengan garis kemiskinan yaitu $S V=3$ yang terdapat pada tabel 4.7 terdapat 0 KK(L), 0 KK(P), 3 AK1, 8 AK2, 6 AK3,dan 4 AK4, 2 AK5, 1 AK6, dan 1 AK7 yang memiliki skor kebijakan pemerintah di bawah garis kemiskinan atau sama dengan garis kemiskinan spiritual. Setelah adanya program penyaluran zakat produktif YDSF 0 KK(L), 0 KK(P), 3 AK1, 7 AK2, 6 AK3,dan 4 AK4, 2 AK5, 1 AK6, dan 1 AK7. Dari data tersebut, terdapat perubahan skor kebijakan pemerintah yaitu pada AK-2, sebelum mendapatkan bantuan dana terdapat 0 AK-2, namun setelah adanya bantuan dana zakat terdapat 1 anggota kelvarga yang memiliki nilai diatas SV.

\section{SIMPULAN}

Berdasarkan hasil penelitian pengaruh zakat produktif terhadap kondisi mustahiq sebelum dan sesudah menerima bantuan dana dari Yayasan Dana Sosial AlFalah (YDSF) Surabaya yang dikaji dengan menggunakan pendekatan metode CIBEST, terlihat perubahan kondisi kesejahteraan mustahiq sesudah menerima zakat produktif YDSF, seperti meningkatnya nilai indeks kesejahteraan dan penurunan nilai indeks kemiskinan material maupun spiritual.

\section{DAFTAR PUSTAKA}

Anshori Muslich dan Sri Iswati. 2009. Metode Penelitian Kuaantitatif. Surabaya: Airlangga University Press (AUP)

Asnaini. 2008. Zakat Produktif Dalam Perspektif Hukum Islam. Bengkulu: Pustaka Pelajar.
Azam, M., lqbal, N., \& Tayyab, M. (2014). Zakat and Economic Development: Micro and Macro Level Evidence from Pakistan. Bulletin of Business and Economics, 3(2), 85-95.

Badan Pusat Statistik (BPS). 2016. Profil Kemiskinan di Indonesia Maret 2018. dalam Berita Resmi Statistik, edisi No.57/07/Th.XXI, 16 Juli 2018. Badan Pusat Statistik. Jakarta.

Badan Pusat Statistik (BPS). 2016. Profil Kemiskinan Kota Surabaya 2018. dalam Berita Resmi Statistik, edisi No.01/01/3578/ Th.ll, 04 Januari 2018. Badan Pusat Statistik. Jakarta.

Beik IS, Arsyianti LD. 2015. Ekonomi Pembangunan Syariah. Bogor (ID) edisi revisi : IPB Press.

Fakhruddin. 2008. Fikih dan Manajemen Zakat di Indonesia. Malang: UIN Malang Press

Firdausi, Hilya. 2015. "Peran Dana Zakat Produktif Dalam Mengembangkan Usaha Mustahik (Studi Kasus Pada Lembaga Amil Zakat Masjid Al Akbar Surabaya). Skripsi. Surabaya: Fakultas Ekonomi dan Bisnis, Universitas Airlangga.

Imaduddin Abi Al-Fida'i Ismail Ibn Katsir AlQurasyiyyi. 1995. Tafsir Al-Qur'an AlAzhim jilid 2. Riyadh: Daar 'Alimi AlKutub.

Hamzah Hasan Khaeriyah. 2008. Ekonomi Islam, Kerangka Fikir dan Istrumen Ekonomi Zakat Serta Wasiat. Jakarta: Lekas. 
Ashar, et al/Jurnal Ekonomi Syariah Teori dan Terapan Vol. 6 No. 5 Mei 2019: 1057-1071; IMPLEMENTASI METODE CIBEST (CENTER OF ISLAMIC BUSINESS AND ECONOMIC STUDIES) DALAM MENGUKUR PERAN ZAKAT PRODUKTIF TERHADAP PEMBERDAYAAN MUSTAHIQ DI LEMBAGA YAYASAN DANA SOSIAL ALFALAH (YDSF) SURABAYA

Hikmat Kurnia, dan A Hidayat. 2008.

Panduan Pintar Zakat. Jakarta:

Qultum Media.

Nindityo, Herwindo Ghora.2014."Zakat

Produktif Untuk Meningkatkan

Kinerja Produksi, Motivasi, dan

Religuitas Mustahik (Studi Kasus

Pada BAZ Jatim)". Skripsi. Surabaya:

Fakultas Ekonomi dan Bisnis,

Universitas Airlangga.

Sugiyono. 2009. Metode Penelitian

Kuantitatif, Kualitatif Dan R\&D.

Bandung: Alfabeta.

Sugiyono. 2017. Metode Penelitian

Kuantitatif, Kualitatif dn R\&D.

Bandung: Alfabeta

Tarigan, Josep R., M. Suparmoko. 2000.

Metode Pengumpulan Data : Untuk

IImu Sosial dan Ekonomi. Jilid 1.

Yogyakarta : BPFE.

Yusuf Qardhawi. 2007. Hukum Zakat. Jakarta

: Lentera Antar Nusa

http://www.bps.go.id/ , dikases pada

tanggal 23 Maret 2017

http://www.surabayakota.bps.go.id/,

diakses pada tanggal2 Juni 2017

http://www.ydsf.org, diakses pada tanggal

2 Juni 2017 